\title{
Is It Safe to Proceed with Thrombolytic Therapy for Acute Ischemic Stroke in a Patient with Cardiac Myxoma? Case Report and Review of the Literature
}

\author{
Ivan Rocha Ferreira da Silva ${ }^{a} \quad$ Gabriel R. de Freitas ${ }^{b}$ \\ ${ }^{a}$ Neurocritical Care Unit, Cerebrovascular Center, Cleveland Clinic Foundation, Cleveland, Ohio, USA; ${ }^{b}$ Service of Neurology, \\ Hospital Quinta D'Or/Instituto D'Or, Institute for Research and Education (IDOR), Rio de Janeiro, Brazil
}

Dear Sir,

Acute cerebral ischemia can be the first manifestation of an atrial myxoma $[1,2]$. Myxomas are the most common primary cardiac tumors and can present as mitral valve dynamic obstruction, constitutional symptoms or embolic phenomena.

We currently present the case of a 69-year-old woman with a history of hypertension who presented with sudden leftsided hemiparesis, drowsiness, and left hemineglect, with a National Institutes of Health Stroke Scale (NIHSS) score of 12. She reported having experienced the same symptoms $1 \mathrm{~h}$ earlier, with prompt recovery after a few minutes. Magnetic resonance imaging (MRI) of the brain was performed at the emergency department, showing an acute ischemic infarct in the right basal ganglia and semi-oval white matter, and a MR angiography disclosed an occlusion of the right middle cerebral artery (MCA). The stroke team decided to proceed with thrombolytic treatment using intravenous recombinant tissue plasminogen activator (rtPA). The medication was infused uneventfully within $120 \mathrm{~min}$ from the beginning of her symptoms. The patient presented some clinical improvement after the infusion, with a decrease of her NIHSS score of 7 points, sustained throughout the next 24 h. A transcranial Doppler and a digital cerebral angiography were performed, confirming the reperfusion of the right MCA, with only minimal slowing of the distal flow. The next morning, she was started on aspirin $100 \mathrm{mg} /$ daily and enoxaparin 40 $\mathrm{mg} /$ daily for stroke and deep venous thrombosis prevention. Later that day, the patient presented a worsening of her clinical status secondary to an embolic occlusion of her left femoral artery. Moreover, a transthoracic echocardiogram disclosed a $2 \times 2 \mathrm{~cm}$ mass inside the left atrium, raising suspicion of an atrial myxoma. She underwent urgent peripheral vascular and cardiac surgeries, which confirmed the finding of a left atrial myxoma. The blood pressure fluctuated throughout the lengthy surgery, with reported episodes of hypotension, and blood loss was estimated at approximately 1 liter. During the postoperative period, her neurological status deteriorated and an urgent computerized tomography scan was performed, showing diffuse parenchymal edema over the right MCA distribution, with associated midline shift. Urgent decompressive craniectomy was performed, but no clinical improvement was achieved. The patient evolved to brain death within the next $24 \mathrm{~h}$.

\section{Review of the Literature}

Eight previous reports presented patients with acute ischemic strokes and associated cardiac myxoma treated with thrombolytic therapy [3-10]. The majority of those patients (6) were treated with alteplase, 4 of which received it intravenously [3-6], and 2 intra-arterially $[7,8]$. The 2 remaining reports used intra-arterial uroki- nase $[9,10]$. All but 1 patient were treated within $270 \mathrm{~min}$ [9]. The clinical improvement was described as positive in 7 reports [3-9], though NIHSS score was not reported in most of them, and only 1 patient suffered a major bleeding (cerebellar hemorrhage and mild parietal subarachnoid bleeding), but still with a positive outcome [3]. The definition of improvement was obtained from each report according to the definition of its authors (most authors did not report pre- and/or post-treatment NIHSS scores). Table 1 summarizes the reports, showing their main characteristics.

\section{Discussion}

Treatment of acute ischemic strokes caused by embolic atrial myxoma is controversial, largely because the embolus could be composed of the tumor itself, adhered thrombotic material or a combination of both. It is reasonable to argue for the possible mechanism of action of rtPA depending on the composition of the emboli; however, the current guidelines for acute ischemic stroke do not address this question. Moreover, previous autopsy studies showed the presence of aneurysms in the cerebral vessels of these patients, probably secondary to tumoral invasion and inflammation of the arterial layers, raising concern about the occurrence of subarachnoid hemorrhage during chemical thrombolysis [11].

\section{KARGER}

Fax +4161306 1234 E-Mail karger@karger.ch www.karger.com (c) 2012 S. Karger AG, Basel

0014-3022/12/0683-0185\$38.00/0

Accessible online at: www.karger.com/ene
Ivan Rocha Ferreira da Silva, MD

Neurocritical Care Unit, Cerebrovascular Center

Cleveland Clinic Foundation, 1132 Churchill Road

Lyndhurst, OH 44124 (USA)

Tel. +1 832398 9384, E-Mail ivanuerj@gmail.com 
Table 1. Descriptive compilation of reported cases of patients with acute ischemic stroke secondary to atrial myxoma treated with thrombolysis

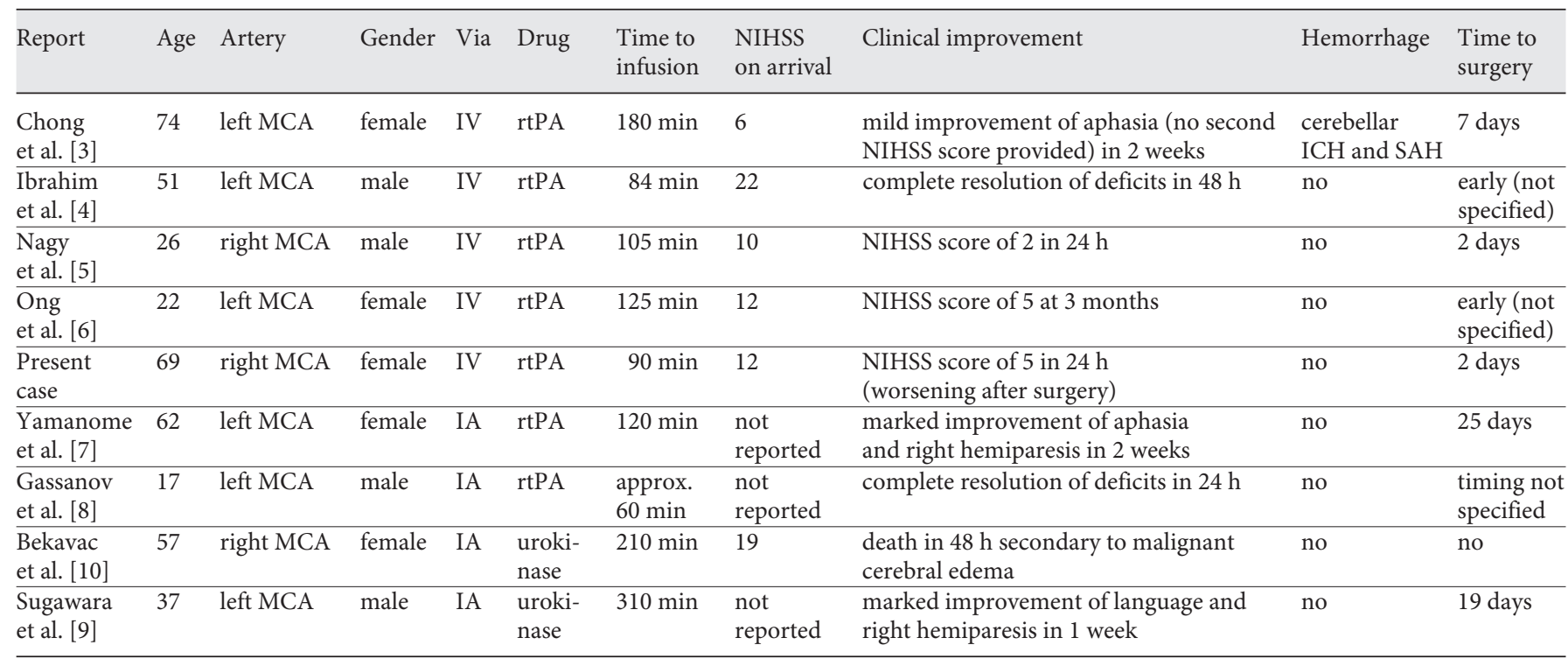

IA = Intra-arterial; IV = intravenous; SAH = subarachnoid hemorrhage; ICH = intracerebral hemorrhage.

Initially, our patient presented a satisfactory improvement (both clinically and on imaging) with intravenous rtPA. We believe that the unfavorable outcome was most likely due to hemodynamic instability during the surgical procedures which led to massive cerebral ischemia in an already vulnerable brain with recovering areas of penumbra after successful thrombolysis.

\section{References}

1 Joynt RJ, Zimmerman G, Khalifeh R: Cerebral emboli from cardiac tumors. Arch Neurol 1965;12:84-91.

-2 Reynen K: Cardiac myxomas. N Engl J Med 1995;333:1610-1617.

>3 Chong JY, Vraniak P, Etienne M, et al: Intravenous thrombolytic treatment of acute ischemic stroke associated with left atrial myxoma: a case report. J Stroke Cerebrovasc Dis 2005;14:39-41.

-4 Ibrahim M, Iliescu C, Safi HJ, Buja ML, McPherson DD, Fuentes F: Biatrial myxoma and cerebral ischemia successfully treated with intravenous thrombolytic therapy and surgical resection. Tex Heart Inst J 2008;35: 193-195.
It is difficult to draw a firm conclusion from the few existing data which consist of single-case reports employing a variety of methods of administering different thrombolytic drugs. A reasonable hypothesis is that intra-arterial infusion may be safer than intravenous infusion, given the opportunity to evaluate the existence of aneurysms prior to infusing the thrombolytic. On the other hand, just one report of intravenous infusion showed hemorrhagic events, with a corresponding normal cerebral angiography. It is worth mentioning that the current guidelines on stroke thrombolysis do not recommend against it in patients with atrial myxoma. In conclusion, we believe that patients with a known history of atrial myxoma should not be excluded from receiving chemical thrombolysis, either given intra-arterially or intravenously. Mechanical thrombolysis could also be an exciting alternative.
5 Nagy CD, Levy M, Mulhearn TJ 4th, Shapland M, Sun H, Yuh DD, Cheung D, Chandra-Strobos N: Safe and effective intravenous thrombolysis for acute ischemic stroke caused by left atrial myxoma. J Stroke Cerebrovasc Dis 2009;18:398-402.

6 Ong CT, Chang RY: Intravenous thrombolysis of occlusion in the middle cerebral and retinal arteries from presumed ventricular myxoma. Stroke Res Treat 2010;2011:735057.

7 Yamanome T, Yoshida K, Miura K, et al: Superselective fibrinolysis for a middle cerebral artery embolism caused by a left atrial myxoma: case report (in Japanese). No Shinkei Geka 2000;28:653-658.
8 Gassanov N, Nia AM, Dahlem KM, Ederer S, Wedemeyer I, Caglayan E, Erdmann E, Er F: Local thrombolysis for successful treatment of acute stroke in an adolescent with cardiac myxoma. Scientific World Journal 2011;11:891-893.

9 Sugawara T, Takahashi A, So K, Yoshimoto T, Suzuki J, Suzuki Y, Horiuchi T: A case of cerebral embolism caused by atrial myxoma - superselective fibrinolytic therapy (in Japanese). No Shinkei Geka 1987;15:1321-1326.

10 Bekavac I, Hanna JP, Wallace RC, et al: Intraarterial thrombolysis of embolic proximal middle cerebral artery occlusion from presumed atrial myxoma. Neurology 1997;49: 618-620.

-11 Josephson SA, Johnston SC: Multiple stable fusiform intracranial aneurysms following atrial myxoma. Neurology 2005;64:526. 